\title{
The hydrogenosomes of Psalteriomonas lanterna
}

\author{
Rob M de Graaf ${ }^{\dagger 1}$, Isabel Duarte ${ }^{\dagger 2}$, Theo A van Alen ${ }^{1}$, Jan WP Kuiper ${ }^{1,4}$, \\ Klaas Schotanus ${ }^{1,5}$, Jörg Rosenberg 3 , Martijn A Huynen ${ }^{2,6}$ and \\ Johannes HP Hackstein*1
}

\begin{abstract}
Address: ${ }^{1}$ Department of Evolutionary Microbiology, IWWR, Radboud University Nijmegen, Heyendaalseweg 135, 6525AJ Nijmegen, The Netherlands, ${ }^{2}$ Center for Molecular and Biomolecular Informatics, Nijmegen Center for Molecular Life Sciences, Radboud University Nijmegen Medical Centre, Geert Grooteplein 28, 6525GA Nijmegen, The Netherlands, ${ }^{3}$ Sommerhaus 45, D-50129 Bergheim, Germany, ${ }^{4}$ CIHR Group in Matrix Dynamics, University of Toronto, 150 College Street, Toronto, Ontario, Canada M5S 3E2, 5 Department of Ecology and Evolutionary Biology, 106A Guyot Hall, Princeton University, Princeton NJ 08554-2016, USA and ${ }^{6}$ Netherlands Bioinformatic Centre, Geert Grooteplein 28, 6525 GA Nijmegen, The Netherlands
\end{abstract}

Email: Rob M de Graaf - exorest@science.ru.nl; Isabel Duarte - i.duarte@cmbi.ru.nl; Theo A van Alen - T.vanAlen@science.ru.nl; Jan WP Kuiper - J.Kuiper@science.ru.nl; Klaas Schotanus - kschotan@princeton.edu; Jörg Rosenberg - sommerhaus-rosenberg@t-online.de; Martijn A Huynen - huynen@cmbi.ru.nl; Johannes HP Hackstein* - j.hackstein@science.ru.nl

* Corresponding author †Equal contributors

Published: 9 December 2009

BMC Evolutionary Biology 2009, 9:287 doi:10.1 |86/147|-2/48-9-287
Received: 20 July 2009

Accepted: 9 December 2009

This article is available from: http://www.biomedcentral.com/I47|-2|48/9/287

(C) 2009 de Graaf et al; licensee BioMed Central Ltd.

This is an Open Access article distributed under the terms of the Creative Commons Attribution License (http://creativecommons.org/licenses/by/2.0), which permits unrestricted use, distribution, and reproduction in any medium, provided the original work is properly cited.

\begin{abstract}
Background: Hydrogenosomes are organelles that produce molecular hydrogen and ATP. The broad phylogenetic distribution of their hosts suggests that the hydrogenosomes of these organisms evolved several times independently from the mitochondria of aerobic progenitors. Morphology and I8S rRNA phylogeny suggest that the microaerophilic amoeboflagellate Psalteriomonas lanterna, which possesses hydrogenosomes and elusive "modified mitochondria", belongs to the Heterolobosea, a taxon that consists predominantly of aerobic, mitochondriate organisms. This taxon is rather unrelated to taxa with hitherto studied hydrogenosomes.
\end{abstract}

Results: Electron microscopy of $P$. lanterna flagellates reveals a large globule in the centre of the cell that is build up from stacks of some 20 individual hydrogenosomes. The individual hydrogenosomes are surrounded by a double membrane that encloses a homogeneous, dark staining matrix lacking cristae. The "modified mitochondria" are found in the cytoplasm of the cell and are surrounded by I-2 cisterns of rough endoplasmatic reticulum, just as the mitochondria of certain related aerobic Heterolobosea. The ultrastructure of the "modified mitochondria" and hydrogenosomes is very similar, and they have the same size distribution as the hydrogenosomes that form the central stack.

The phylogenetic analysis of selected EST sequences (Hsp60, Propionyl-CoA carboxylase) supports the phylogenetic position of $P$. lanterna close to aerobic Heterolobosea (Naegleria gruberi). Moreover, this analysis also confirms the identity of several mitochondrial or hydrogenosomal key-genes encoding proteins such as a Hsp60, a pyruvate:ferredoxin oxidoreductase, a putative ADP/ATP carrier, a mitochondrial complex I subunit (5I KDa), and a [FeFe] hydrogenase.

Conclusion: Comparison of the ultrastructure of the "modified mitochondria" and hydrogenosomes strongly suggests that both organelles are just two morphs of the same organelle. The EST studies suggest that the hydrogenosomes of $P$. lanterna are physiologically similar to the hydrogenosomes of Trichomonas vaginalis and Trimastix pyriformis. Phylogenetic analysis of the ESTs confirms the relationship of $P$. lanterna with its aerobic relative, the heterolobosean amoeboflagellate Naegleria gruberi, corroborating the evolution of hydrogenosomes from a common, mitochondriate ancestor. 


\section{Background}

Aerobic eukaryotes possess classical mitochondria, but anaerobic eukaryotes can host very diverse organelles that belong to a broad spectrum of double-membrane bounded, mitochondria-related compartments. These organelles range from full-fledged, but anaerobic mitochondria to tiny "mitosomes" with a minimal protein content. Examples of these anaerobic functioning organelles are the "mitochondria-like" organelles of Blastocystis [1], the "mitochondrial remnant" of Cryptosporidium [2], the "hydrogenosomes" of Trichomonas [3] and the "mitosomes" of Giardia, Entamoeba, and Trachipleistophora [4-6]. Anaerobic mitochondria, mitochondria-like organelles and hydrogenosomes produce ATP, albeit with either different electron transport chains than in aerobic mitochondria, or without an electron transport chain altogether. Mitosomes do not produce ATP - they seem to host only enzymes engaged in Fe-S cluster biogenesis [7]. The presence of these proteins appears to be the only property that is shared between all members of the mitochondrial family, perhaps with the exception of the mitosomes of Entamoeba histolytica and Mastigamoeba balamuthi where the corresponding proteins are likely to be localized in the cytoplasm [8-10]. Hydrogenosomes produce molecular hydrogen with the aid of one or several hydrogenases. They are double-membrane bounded organelles sized approximately $0.5-2 \mu \mathrm{m}$. They are found in a broad spectrum of unicellular, anaerobic (or microaerophilic) protists such as parabasalid flagellates (Trichomonas vaginalis, Tritrichomonas foetus, Histomonas meleagridis), excavate, preaxostylid flagellates (Trimastix pyriformis), heterolobosean amoeboflagellates (Psalteriomonas lanterna), anaerobic ciliates (e.g. Nyctotherus ovalis, Metopus palaeformis, Trimyema compressum, Caenomorpha uniserialis, Dasytricha ruminantium), and anaerobic chytridiomycete fungi (Neocallimastix sp., Piromyces sp.). The broad phylogenetic distribution of their hosts suggests that the hydrogenosomes of these organisms evolved several times independently. Accordingly, hydrogenosomes are not the same, they differ structurally and metabolically [11-14]. However, it is likely that all these various hydrogenosomes produce ATP by substrate-level phosphorylation. Besides ATP and hydrogen, most of them produce $\mathrm{CO}_{2}$ and acetate as end products of their carbohydrate metabolism. Nyctotherus ovalis produces succinate in addition, and the ciliate Trimyema compressum as well as the anaerobic chytrids Neocallimastix sp. and Piromyces sp. produce formate as one of their metabolic end products $[11,12,15,16]$. The major substrate of the carbohydrate catabolism of hydrogenosomes is pyruvate that is metabolized by either pyruvate:ferredoxin oxidoreductase (PFO) as in Trichomonas or pyruvate:formate lyase (PFL) as in Neocallimastix and Piromyces $[15,17]$. Notably, Nyctotherus ovalis uses pyruvate dehydrogenase (PDH) as aer- obic mitochondria do [16]. For their major redoxreactions, hydrogenosomes use ferredoxins or components of a mitochondrial or bacterial complex I. [18,19].

Evidence from morphology and $18 \mathrm{~S}$ rRNA phylogeny suggests that the microaerophilic amoeboflagellate Psalteriomonas lanterna belongs to the Heterolobosea, a taxon that consists predominantly of aerobic, mitochondriate organisms [20-23]. Only three related anaerobic organisms, the amoebae Vahlkampfia anaerobica, Monopylocystis visvesvarai and Sawyeria marylandensis have been described. While the lack of molecular data does not allow a closer determination of the phylogenetic position of Vahlkampfia anaerobica, 18S rRNA data clearly reveal that the latter two amoebae are close relatives of Psalteriomonas lanterna [22-24]. The flagellate stage of Psalteriomonas lanterna hosts a large globular hydrogenosomal complex that is associated with numerous endosymbiotic methanogens [20]. Remarkably, it also hosts 0.6 - $3.0 \mu \mathrm{m}$ sized cytoplasmic organelles that were interpreted as "modified mitochondria" $[20,25]$. If this interpretation is true, it would make Psalteriomonas unique in having both mitochondria and hydrogenosomes which are normally mutually exclusive. The large, globular organelles were identified as hydrogenosomes using a cytochemical reaction (BSTP staining, c.f. [26]) to detect hydrogenase activity and the organelle's reaction with a heterologous antibody against hydrogenase [25]. The "modified mitochondria" reacted only weakly with the antibody and were not analyzed in more detail. Physiological studies were not performed since P. lanterna cannot be cultured axenically. Molecular information is restricted to the DNA sequence of a ferredoxin and the $18 \mathrm{~S}$ rRNA gene; the latter allowed the determination of the phylogenetic position of P. lanterna as belonging to the Percolozoa (Heterolobosea) with a sistergroup relationship to the Vahlkamphidae [21-23,27].

Here we present a combined electron microscopic and molecular study that aims to unravel the structure and function of the hydrogenosomes and the presumed "modified mitochondria" of Psalteriomonas lanterna. We describe the ultrastructure of the "modified mitochondria" and hydrogenosomes in detail and provide evidence that both organelles are actually two morphs of the same organelle and not two different organelles. Moreover, we provide molecular information from preliminary EST studies on the phylogenetic position with respect to the aerobic relatives and the potential function of the hydrogenosomes. These studies suggest that the hydrogenosomes of $P$. lanterna are physiologically similar to the hydrogenosomes of Trichomonas vaginalis and Trimastix pyriformis $[17,28]$. Phylogenetic analysis of the ESTs confirms the relationship of $P$. lanterna with its aerobic relative, the heterolobosean amoeboflagellate Naegleria 
gruberi. This organism is a free-living soil and freshwater amoeboflagellate and closely related to the pathogenic Naegleria fowleri that can cause severe amoebic meningitis.

\section{Results and discussion Electron microscopy}

Light microscopy of Psalteriomonas lanterna flagellates reveals a large globule in the centre of the cell (Fig. 1a). This globule had been identified as a hydrogenosome by its reaction with an antiserum against hydrogenase and activity staining for hydrogenase with the aid of the BSTP reaction [25]. Also in the amoeba stage this globule is present but less prominently shaped (Fig. 1b). DAPI - and ethidium bromide staining of the globule for nucleic acids were negative (not shown).

When the hydrogenosomes of Psalteriomonas lanterna were described for the first time at the electron microscopy level, they were seen to form globules consisting of closely packed "microbodies" intermingled with symbiotic methanogenic archaea [20]. In some cases the hydrogenosomes (microbodies) were penetrated by methanogens [25]. Notably, the analysis of symbiont-free cells revealed that the hydrogenosomes also assembled into globules in the absence of methanogenic archaea. After more than 20 years of cultivation, all Psalteriomonas lanterna cells became free of methanogens as judged by the absence of methane production and the specific $\mathrm{F}_{420}$ autofluorescence [29] (data not shown). Electron microscopical analysis confirms the absence of methanogens and reveals that the central globule is a large complex built up from stacks of more than 20 individual hydrogenosomes, which are predominantly sausage- and dumbbell-shaped (Fig. 2c, d). Individual hydrogenosomes are surrounded by a double membrane that encloses a homogeneous, dark staining matrix (Fig. 2d). In a few cells, up
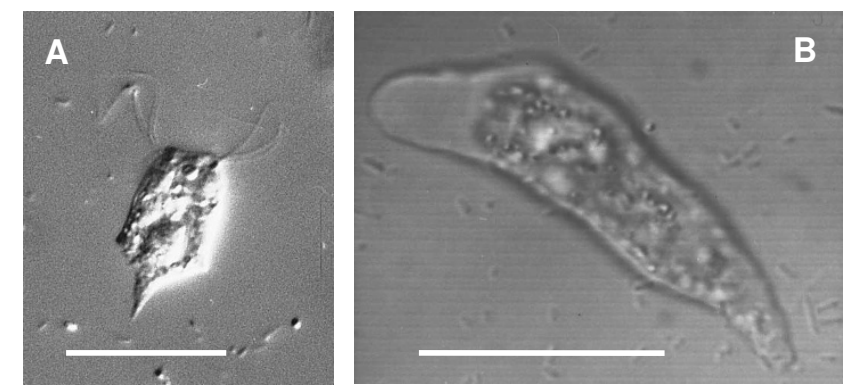

\section{Figure I}

Light microscopy of Psalteriomonas lanterna. A: Flagellate stage of Psalteriomonas lanterna DIC-microscopy. At the apical side of the cell two of the four flagella clusters can be seen. The globule in the centre of the cell is the hydrogenosomal complex. B: Amoeba stage of Psalteriomonas lanterna. CLS-microscope. Bars: $30 \mu \mathrm{m}$
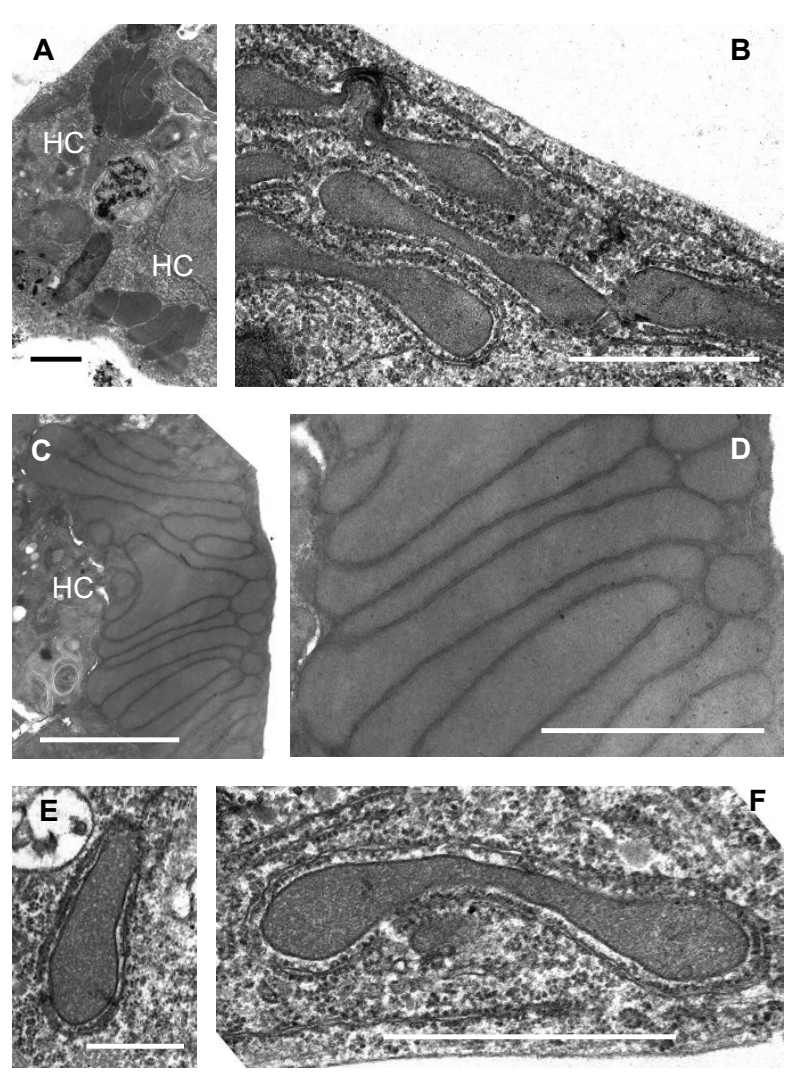

\section{Figure 2}

Electron microscopy of the hydrogenosomes of Psalteriomonas lanterna flagellates. A: Cell with two small stacks of hydrogenosomes. HC: hydrogenosomal complex. B: Group of dumb-bell-shaped hydrogenosomes in the periphery of the cell. The hydrogenosomes are surrounded by cisterns of rough endoplasmatic reticulum (rough ER). These organelles have been named "modified mitochondria" by Broers (1992) [25]. C: Large stack of hydrogenosomes (HC). D: Detail of the hydrogenosomal complex shown in C. E: "Single" hydrogenosome surrounded by rough ER. F: Dumb-bellshaped hydrogenosome ("modified mitochondrion"). Bars A$\mathrm{D}, \mathrm{F}:$ I $\mu \mathrm{m}$; E: $0,5 \mu \mathrm{m}$

to four smaller hydrogenosomal complexes were found; the stacks consist of 5-6 individual hydrogenosomes (Fig. 2a). These stacks are regarded as juvenile complexes.

Broers [20] described "modified mitochondria" in the periphery of the Psalteriomonas lanterna cells, odd organelles that were surrounded by a cistern of rough endoplasmatic reticulum (rough ER). In our study, these "modified mitochondria" look very similar to the individual hydrogenosomes of the hydrogenosomal complex of the globule (Fig. 2b, e, f). The matrix is homogeneous, but less densely stained as in the stacked hydrogenosomes; there is no evidence for the presence of (mitochondrial) 
cristae. All these organelles are surrounded by 1-2 cisterns of rough ER - like the mitochondria of aerobic Heterolobosea, e.g. Tetramitus rostratus, Paratetramitus jugosus, Vahlkampfia aberdonica, Vahlkampfia avara and Vahlkampfia ustiana $[30,31]$. Similarly to the hydrogenosomes in the stack, they are bounded by a double membrane. Most organelles are dumb-bell-shaped (Fig. $2 b, \mathrm{f}$ ), some are sausage-shaped (Fig. 2e), and a few are cup-shaped and similar in appearance to the mitochondria of certain aerobic Heterolobosea, e.g. Vahlkampfia ustiana [31]. Certain dumb-bell- and cup-shaped organelles are rather slim in the middle, suggesting that these organelles might be fission stages similar to the fission stages of Trichomonas vaginalis hydrogenosomes [32]. A biometric analysis of the electron microscopic pictures of the stacked hydrogenosomes and the cytoplasmatic organelles revealed no differences in the length-distribution (Fig. 3). The diameter of the hydrogenosomes and the modified mitochondria show a modal distribution around $0.3 \mu \mathrm{m}$ (range 0.1-0.9, $\mathrm{N}=111$; data not shown). Given the identical distribution of lengths and diameters and the very similar morphology, we conclude that the cytoplasmatic organelles are hydrogenosomes, potentially in young, dividing stages. Absence of staining of the cytoplasmatic organelles in the BSTP reaction at the light microscopic level can be explained either by a lack of hydrogenase activity in the

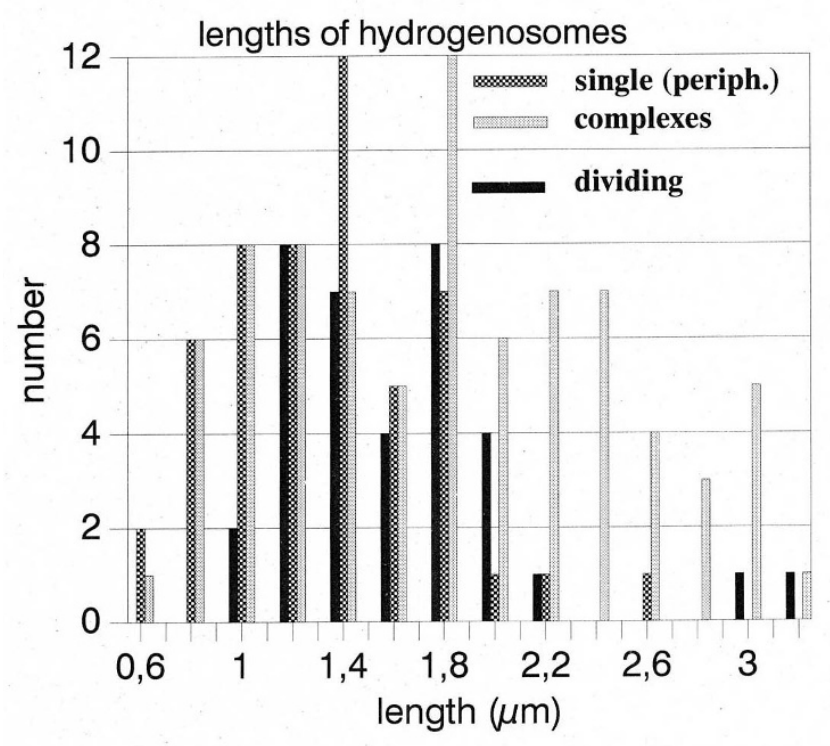

Figure 3

Histogram of the lengths of hydrogenosomes. Randomly selected sections of hydrogenosomes on the electron micrographs were measured and plotted. "dividing": dumbbell-shaped organelles. "complexes": hydrogenosomes from stacks. All kinds of hydrogenosomes belong to the same length distribution. "young" organelles or by an insufficient sensitivity of the BSTP reaction. On the other hand, pictures published by Broers [25] suggest a faint reaction with the hydrogenase antibody. Moreover, both types of organelles stain with Rhodamine-123 as normal mitochondria and hydrogenosomes $[16,25]$. Therefore, it is likely that both the stacked hydrogenosomes and the cytoplasmatic organelles ("modified mitochondria") are morphs (or developmental stages) of the same organelle. It is highly unlikely that hydrogenosomes and mitochondria occur in the same cell, because hydrogenosomes have been identified as a special kind of hydrogen-producing mitochondria $[14,16,18]$. On the other hand, different morphs of mitochondria have been described in the ciliate Euplotes minuta $[33,34]$. The most spectacular example of the presence of different mitochondria in the same organism is the "nebenkern" formation during spermatogenesis in Drosophila where mitochondria aggregate and fuse to form a globule of the same size as the nucleus [35].

\section{ESTs}

About 480 randomly chosen clones were sequenced and analyzed using the BLAST X tool [36]. The clones were single reads of varying length. The genes discussed here (except $51 \mathrm{kDa}$ ) were extended by RT-PCR.

Although the cDNA library was created using poly-d(T) primers, several sequences of bacterial origin were identified that matched with species present in the non-axenic culture. However, bona-fide Psalteriomonas sequences were easily identified by their high A+T content (67-72\%). In addition, a codon usage analysis was performed using the Cusp program from the EMBOSS package [37] and a principal component analysis. These analyses confirmed the homogeneity of the putative Psalteriomonas sequences.

The protein sequences were selected for phylogenetic analysis either because of their usefulness for establishing the phylogenetic position of Psalteriomonas lanterna: Elongation Factor 1 alpha, Hsp60, or for their potential role in the hydrogenosomal metabolism: putative ADP/ATP carrier, $[\mathrm{FeFe}]$ hydrogenase, pyruvate:ferredoxin oxidoreductase (PFO), propionyl-CoA carboxylase (PCCB), Complex I - $51 \mathrm{kDa}$ subunit and glutamate dehydrogenase (GDH).

\section{Elongation Factor I alpha (EF-I alpha)}

During the translation of a mRNA chain in the ribosome, two GTPases play an important role in the elongation cycle: the Elongation factor 2 (EF-2 or EF-G in Prokaryotes) and the Elongation Factor 1 alpha. The EF-1 alpha (EF-Tu in Prokaryotes) is responsible for carrying and promoting the binding of aminoacyl-tRNAs to the A-site of the ribosomal small subunit [38]. 
Since Elongation Factor 1 alpha is present in the three domains of life, i.e., Bacteria, Archaea and Eukaryota, it should be a good phylogenetic marker that might be useful for inferring the phylogenetic position of Psalteriomonas within the eukaryotic tree of life. However, the species distribution within the tree calculated here is not in complete agreement with the eukaryotic tree of life since several species exhibit conspicuous artefactual relationships, particularly the polyphyly of the ciliates and Amoebozoa (Fig 4). Notwithstanding, Psalteriomonas lanterna clusters with Trichomonas vaginalis as seen in several of our phylogenies.

\section{Elongation Factor}

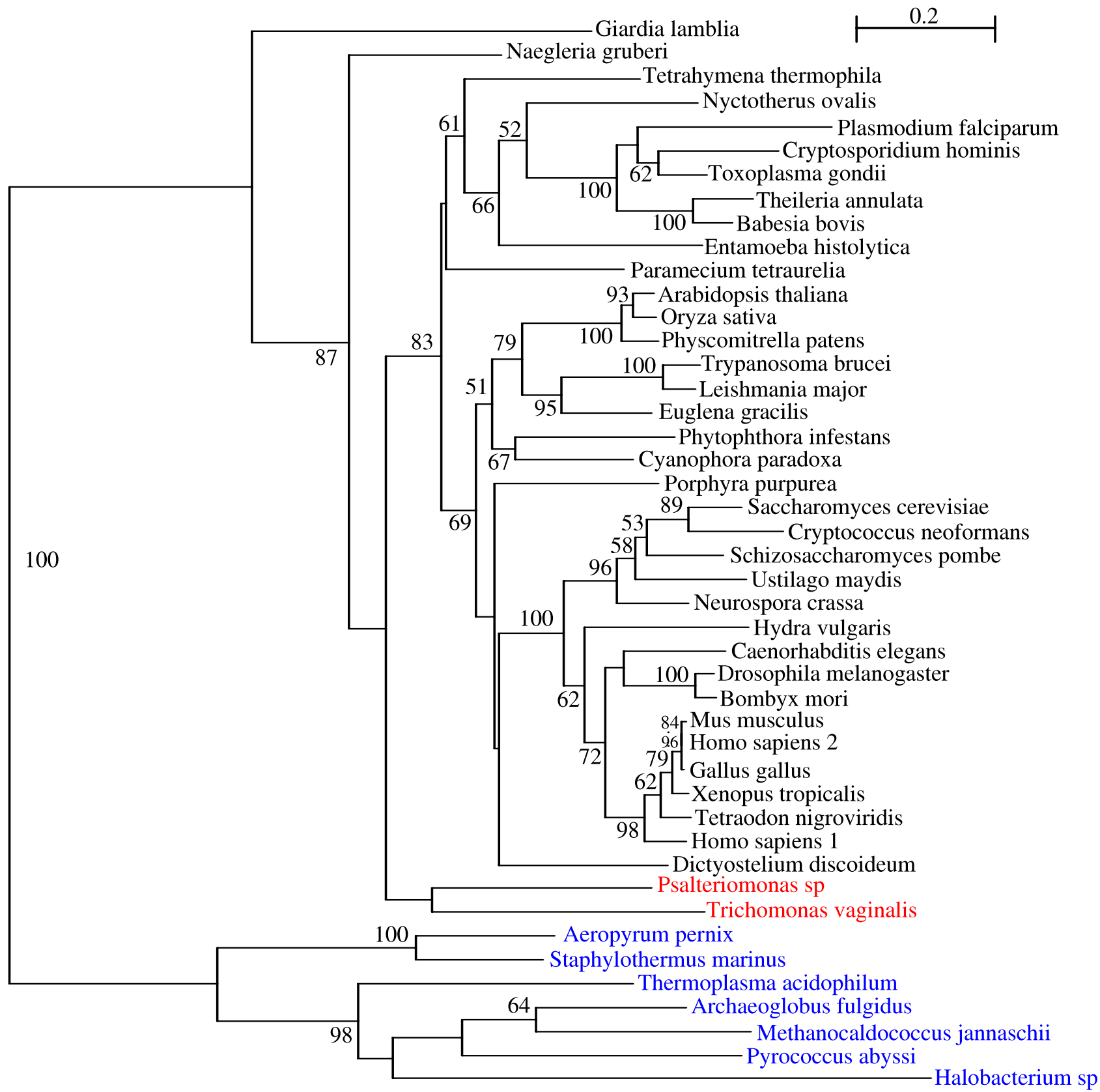

Figure 4

ML tree for the Elongation Factor I alpha. This tree was computed using the RtREV+4 discrete-rate $\mathrm{G}+1+\mathrm{F}$. The tree is rooted by an outgroup of Archaeal species (in blue). Branch values represent the bootstrap percentage. 


\section{Heat shock protein 60 (Hsp60/cpn 60)}

Hsp60 (GroEL/cpn60) is an ATP-dependent, highly conserved protein, involved in protein folding, maturation, renaturation and assembly of complexes, as well as in intracellular cross-membrane shuttling of precursor-protein molecules [39]. In nearly all eukaryotes it is located in the mitochondria, hydrogenosomes or mitosomes.

Its structure resembles a cylindrical barrel, which binds and encloses the folding of proteins in its core [40]. It is an essential and highly conserved protein present in virtually all organisms, shows no evidence of horizontal gene transfer, and is frequently used as a mitochondrial marker [41].

The Hsp60 phylogeny shows the expected eukaryotic branching, and a solid bootstrap supported outgroup of prokaryotic sequences (Fig. 5). Psalteriomonas lanterna and Naegleria gruberi branch together corroborating a close relationship between the mitochondrion of Naegleria gruberi and the hydrogenosomes of Psalteriomonas lanterna. This clustering with $N$. gruberi is consistent with the previously published $18 \mathrm{~S}$ rRNA phylogeny which groups both organisms [21-23]. Furthermore, the clustering of the Het-

hsp60
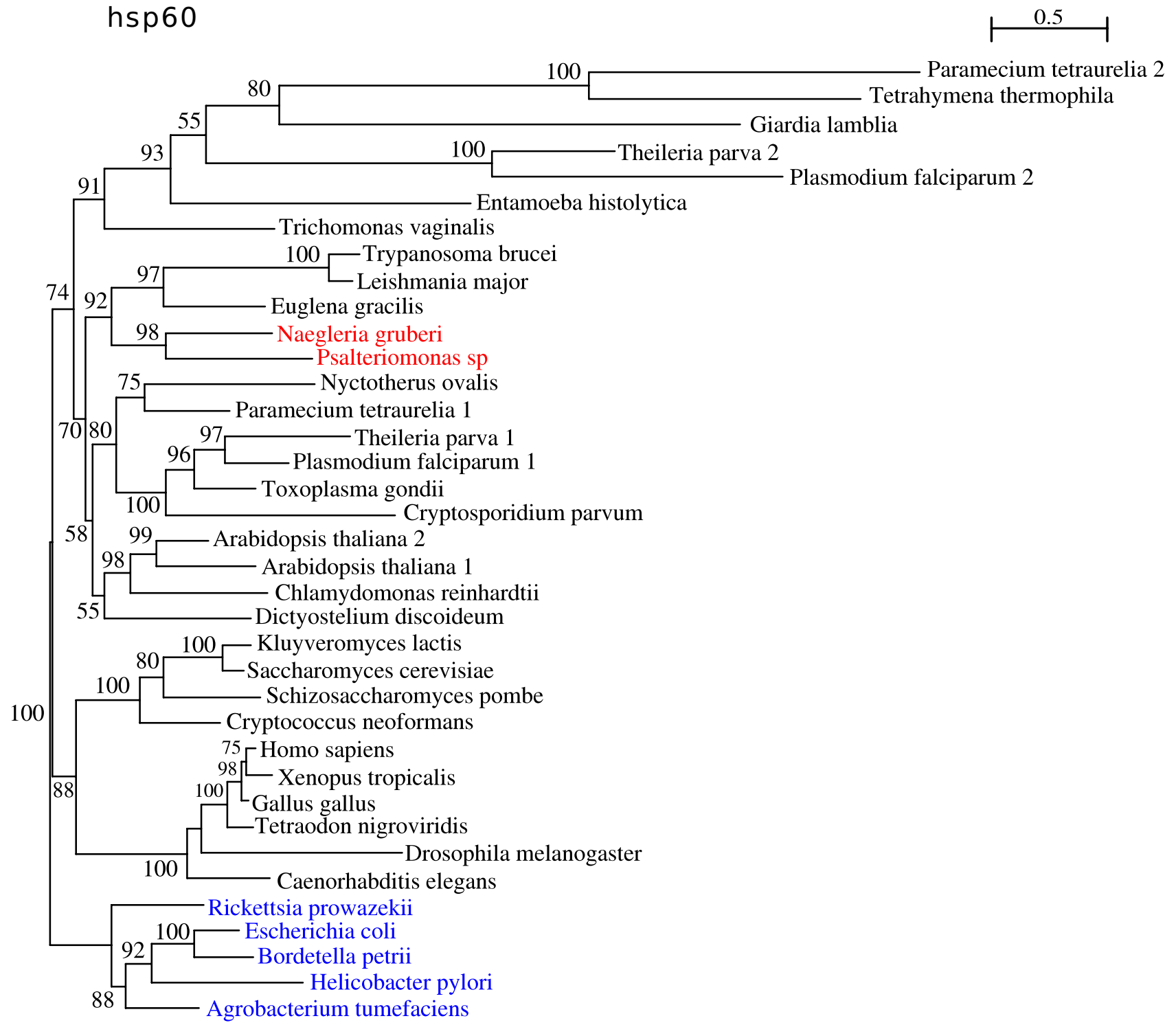

\section{Figure 5}

Phylogeny of the Heat Shock Protein 60. The branch values represent bootstrap values. ML tree computed with $R t R E V+4$ discrete-rate $G+I+F$. An outgroup of Bacteria was chosen to root this tree (in blue). 
erolobosea with the Euglenozoa seen in this tree is consistent with previously published eukaryotic phylogenies [42].

\section{Mitochondrial Solute Carrier (putative ADPIATP Carrier (AAC))}

The ADP/ATP translocator is a member of the Mitochondrial Carrier Family (MCF), which catalyses the transmembrane exchange of ATP produced in the mitochondria (or hydrogenosomes) for cytosolic ADP. All members of this protein family exhibit a tripartite structure which consists of three consecutive sequence repeats of about 100 residues each representing the 3 transmembrane domains [43]. This protein family is exclusively present in Eukaryotes.

All bona-fide mitochondria, but also the hydrogenosomes of Nyctotherus ovalis and Neocallimastix/Piromyces, possess members of the mitochondrial-type ADP/ATP translocator subfamily. The hydrogenosomes of Trichomonas vaginalis and the mitosomes of Entamoeba histolytica and Antonospora locustae do not possess a mitochondrial-type ADP/ATP translocator. Instead they evolved alternative ADP/ATP carriers, which, of course, belong to the mitochondrial carrier family [44]. In addition, the three members of the mitochondrial carrier family of Trimastix pyriformis do not belong to the cluster of genuine mitochondrial-type AACs; their function has not yet been established [28]. While the AAC of Naegleria gruberi clusters within the bona-fide mitochondrial carriers, the mitochondrial carrier protein of Psalteriomonas lanterna assumes an intermediate position between the genuine mitochondrial AACs and the alternative transporters of Trichomonas, Entamoeba and Antonospora (Fig. 6). The phylogenetic position of the mitochondrial carrier protein of Psalteriomonas lanterna argues that this mitochondrial carrier might also be an alternative ADP/ATP carrier. Nevertheless, the alternative possibility, that the mitochondrial carrier protein of Psalteriomonas lanterna is derived from bona-fide AACs cannot be excluded.

\section{[FeFe] Hydrogenase}

Hydrogenases are metalloenzymes that catalyze the reversible reaction that produces dihydrogen using two electrons and two protons. These enzymes are classified in three distinct classes according to the metallic composition of their prosthetic groups: the [Fe]-hydrogenases, only present in methanogenic Archaea; the [NiFe]-hydrogenases, widespread within prokaryotic organisms; and finally, the oxygen sensitive [FeFe]-hydrogenases [45].

[FeFe]-hydrogenases are rather common in anaerobic Bacteria and Archaea, but in eukaryotes its presence is limited to a few species of anaerobic protists, anaerobic chytrid fungi and some green algae. In general, the hydrogenase is located in membrane-bounded organelles, i.e. plastids or hydrogenosomes. In Giardia and Entamoeba the enzyme is located in the cytoplasm [46]. [FeFe]-hydrogenases are generally monomeric and exhibit a multi-domain structure, with a very well conserved active site of ca. 350 residues - the H-cluster - and a variably sized N-terminal domain containing up to four Fe-S clusters [47]. This phylogeny was computed using the H-cluster portion of the protein, due to the modular structure of the hydrogenases, and it positions Psalteriomonas lanterna as a sister group of the algal and fungal hydrogenases (Fig.7).

\section{Pyruvate:Ferredoxin oxidoreductase (PFO)}

Pyruvate is of central importance for the energy metabolism of cells. Its oxidative decarboxylation leads to the formation of acetyl-CoA and $\mathrm{CO}_{2}$. Aerobic species possess a pyruvate dehydrogenase (PDH) multi-enzyme complex, which catalyzes this reaction and specifically reduces $\mathrm{NAD}+$. Anaerobic species in general use another set of specialized enzymes, which reduce low-potential electron carrier proteins, e.g. ferredoxin or flavodoxin, instead of pyridine nucleotides like NAD $[48,49]$. One of these enzymes is the pyruvate:ferredoxin oxidoreductase (PFO), which is present in many eubacteria and archaea, but also in a restricted number of anaerobic eukaryotes, like Trichomonas vaginalis [17], Trimastix pyriformis [28], Giardia lamblia and Entamoeba histolytica [50]. PFO seems not to be present in the aerobic amoeboflagellate Naegleria gruberi. It is regarded as a hallmark protein for hydrogenosomes or organisms with mitosomes [50], although PFO or the related PNO have also been detected in a few organisms with mitochondria, e.g. Euglena and Chlamydomonas. The PFO of Psalteriomonas lanterna branches with the enzymes of Trichomonas vaginalis and Blastocystis, but here is still some discussion regarding the intrinsic function of PFO [51] (Fig. 8). In Blastocystis, which belongs to the Straminopila and which possesses a hydrogenosome-like organelle, two EST clusters encoding a PFO and a PNO (pyruvate:NADP+ ${ }^{+}$oxidoreductase) were identified. Biochemical studies have so far provided only evidence for PNO activity [51].

\section{Propionyl-CoA carboxylase (PCCB)}

Propionyl-CoA carboxylase is a biotin dependent enzyme that catalyses the ATP dependent carboxylation of propionyl-CoA to D-methylmalonyl-CoA. It is involved in the metabolism of odd-chained fatty-acids, cholesterol and the essential amino acids threonine, methionine, valine and isoleucine [52].

The PCC structure consists of two heterologous subunits, alpha and beta, encoded by PCCA and PCCB genes, respectively. The dodecamer enzyme complex is arranged in an alpha6beta6 conformation [53]. 


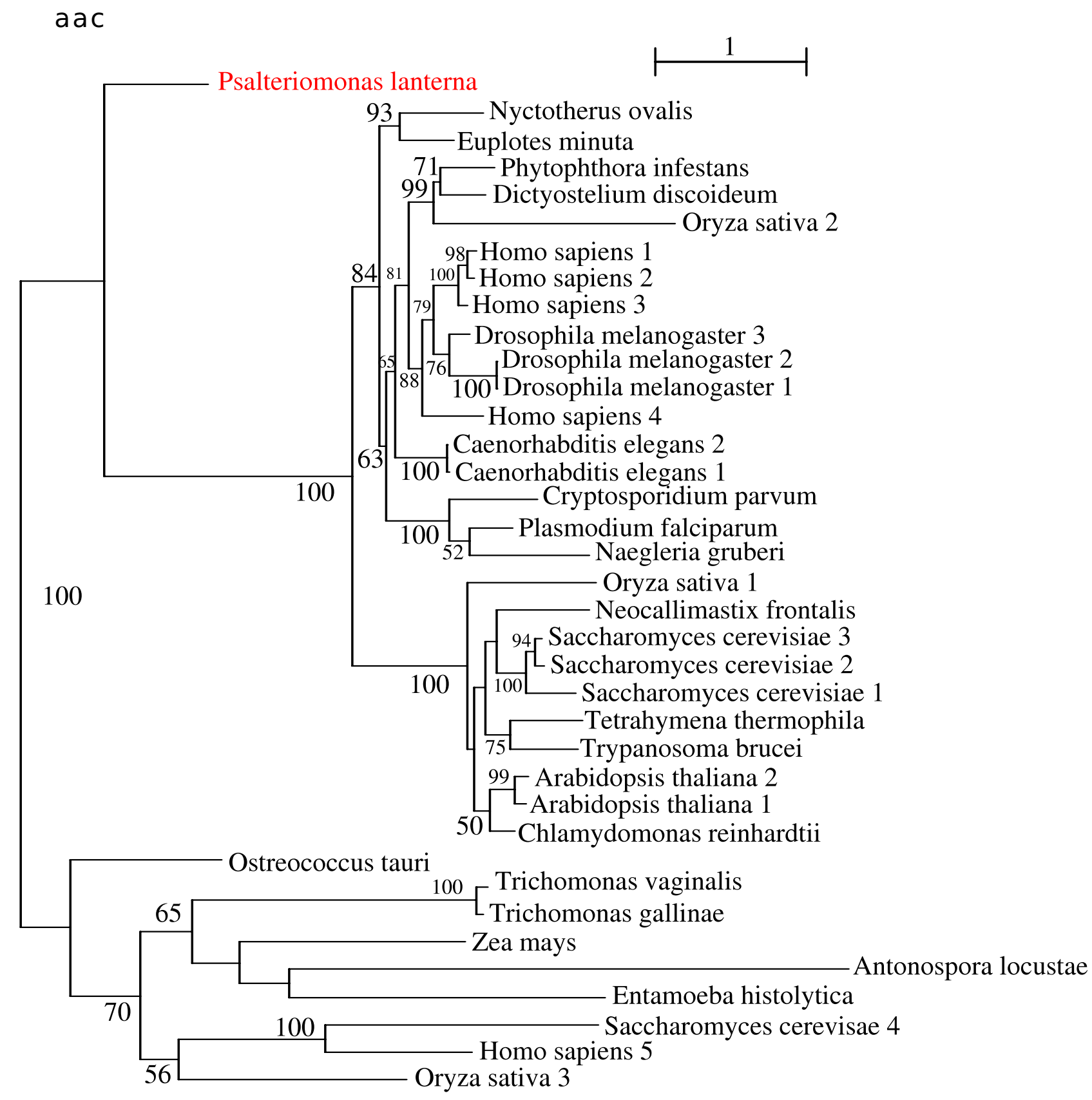

Figure 6

ML phylogeny of the putative ADPIATP carrier (member of the Mitochondrial Solute Carrier family). Branch values are the bootstrap percentages, and the tree was computed using a RtREV+4 discrete-rate G+F.

PCC is involved in metazoan ubiquitous pathways; it has a patchy distribution among other Eukaryotes, suggesting multiple gene loss events $[54,55]$ and it was included in our analysis, because of its location in the mitochondrial matrix and its pivotal metabolic role. The phylogenetic analysis shows a $100 \%$ bootstrap value for the clustering between Psalteriomonas lanterna and Naegleria gruberi (Fig. 9), which is consistent with the results obtained with Hsp60 and points to a close relationship between Naegleria's mitochondrion and Psalteriomonas's hydrogenosome. 


\section{Hydrogenase}
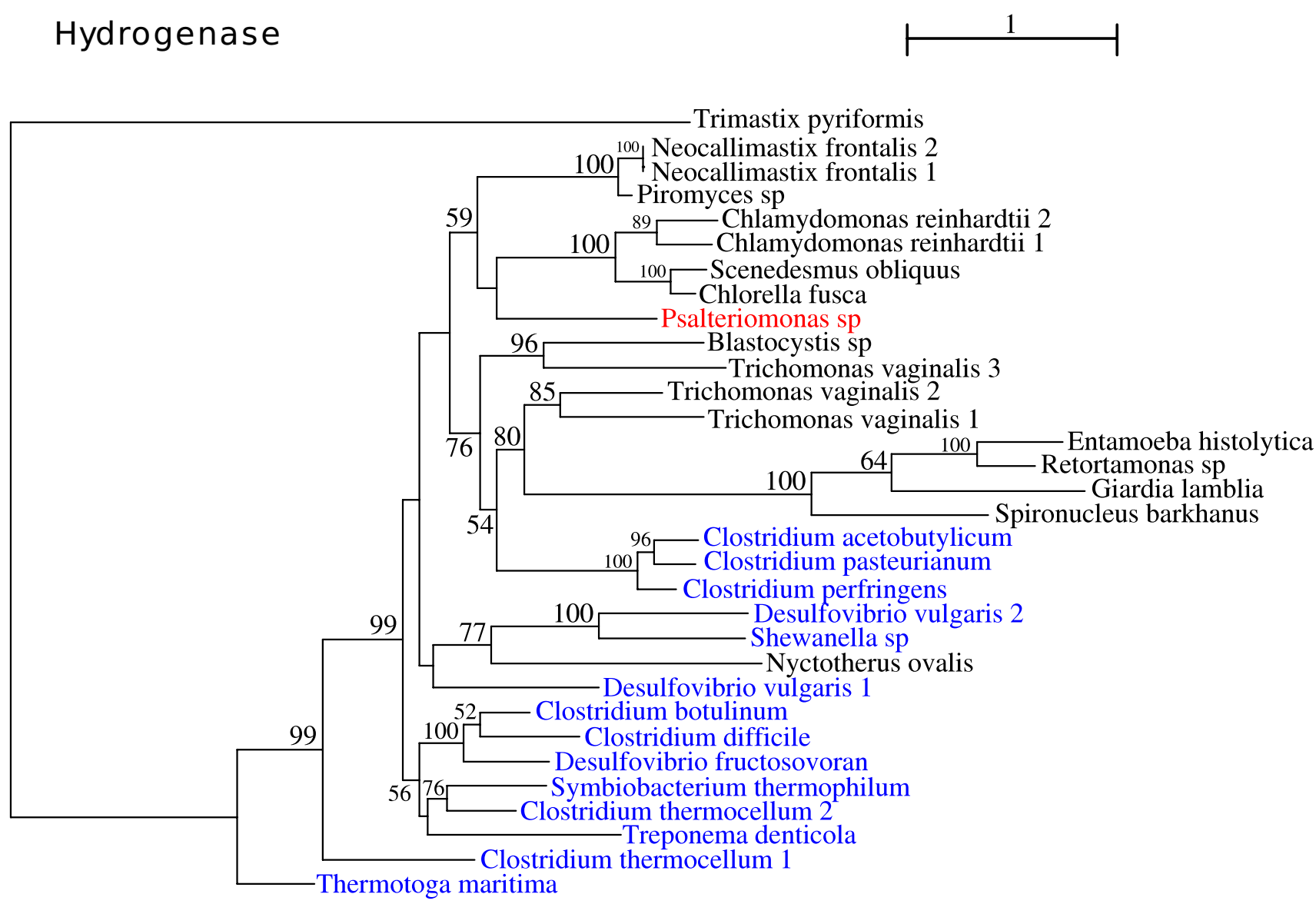

Figure 7

Phylogeny of the [FeFe]Hydrogenase, based on the alignment of the H-cluster. ML bootstrap support values are indicated in the branches. ML computation using a WAG+4 discrete-rate $\mathrm{G}+1+\mathrm{F}$ model.

\section{NADH: ubiquinone oxidoreductase 5 I kDa subunit (Complex I -ndufv I/NuoF)}

NADH: ubiquinone oxidoreductase, commonly known as mitochondrial Complex $\mathrm{I}$, is the largest of the five OXPHOS complexes present in the mitochondrial membrane of aerobic organisms, comprising 45 proteins in human [56]. This protein complex can be divided into 3 functional modules: the dehydrogenase module which is responsible for the oxidation of $\mathrm{NADH}$, the hydrogenase module that shuttles the released electrons, and finally, the transporter module, which pumps protons across the mitochondrial membrane [57]. The $51 \mathrm{kDa}$ subunit, encoded by the ndufv1/nuoF nuclear gene, is an essential part of the dehydrogenase module because it carries the $\mathrm{NADH}$ binding site. Also it binds two co-factors: flavin mononucleotide (FMN) which is an electron carrier molecule that acts as a hydrogen acceptor and one $4 \mathrm{Fe}-4 \mathrm{~S}$ cluster, which captures the electrons released from the NADH oxidation [58]. Despite its role in mitochondrial Complex $\mathrm{I}$, this protein has been found in the absence of most of the remaining proteins of this complex in at least two organisms: Trichomonas vaginalis [59] and Schizosaccharomyces pombe [56], where it is believed to bind and oxidize $\mathrm{NADH}$, potentially functioning as a diaphorase for the hydrogenase. Once again, the link between Psalteriomonas and Trichomonas is present in this phylogeny, showing also that the $51 \mathrm{kDa}$ of Psalteriomonas belongs to the cluster of mitochondrial and alpha-proteobacterial enzymes (Fig. 10).

\section{Glutamate dehydrogenase (GDH)}

Glutamate dehydrogenase (GDH) is a mitochondrial enzyme widely distributed in the three domains of life. It catalyzes the reversible oxidative deamination of glutamate to 2-oxoglutarate and ammonia, using either NAD or NADP as a co-factor. This enzyme is classified in three basic types, according to its co-factor specificity: the NAD specific, the NADP specific and the dual enzyme which accepts either of these. These enzymes are homopolymeres, commonly composed by two to six subunits [60]. 


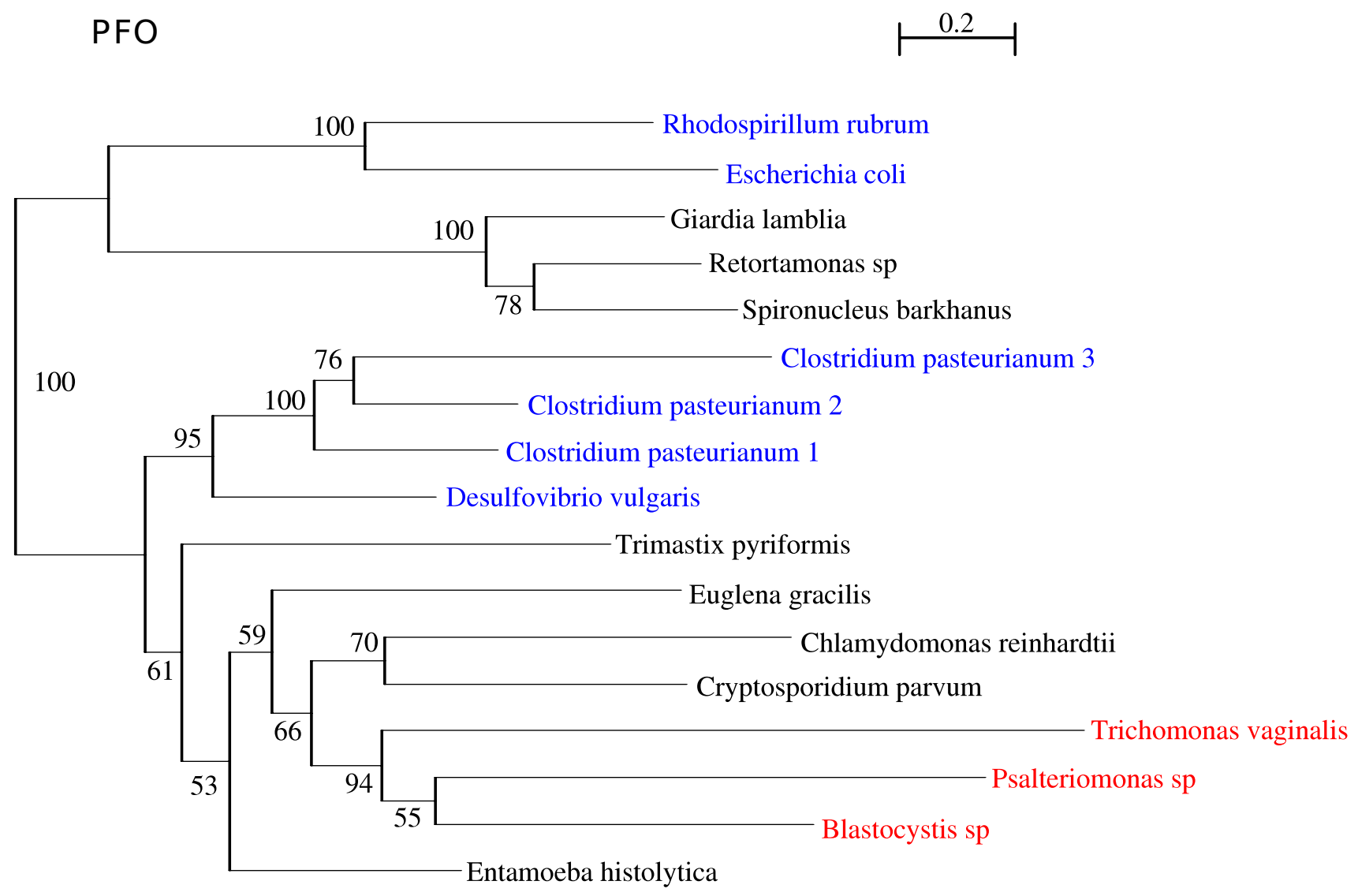

Figure 8

Phylogenetic tree of the Pyruvate:ferredoxin oxidoreductase, computed by ML with WAG+4 discrete-rate $\mathbf{G + I + F}$. Branch support values represent bootstrap values.

While multicellular eukaryotes present only the dual enzyme, fungi have both co-factor specific enzymes and protists possess any combination of dual and specific GDHs [61]. The phylogenetic analysis clusters Psalteriomonas within the Ciona, Spironucleus and Giardia branch (Fig. 11). The position of N. gruberi relative to that of Psalteriomonas is at odds with their relation observed in the PCCB and the Hsp60 phylogeny. Glutamate dehydrogenases show evidence of frequent lateral gene transfer [61], providing an explanation for this inconsistency.

\section{Conclusion}

The hydrogenosomes of Psalteriomonas lanterna are morphologically similar to the mitochondria of its relatives, the aerobic Heterolobosea, if one ignores the absence of cristae in Psalteriomonas lanterna. This becomes evident from their shape, the double membrane, which bounds both types of hydrogenosomes of Psalteriomonas lanterna, and the cisterns of rough ER that surround the cytoplasmic forms of the hydrogenosomes. This is characteristic for the mitochondria of the aerobic Heterolobosea, which, in contrast to the hydrogenosomes of Psalteriomonas lanterna, possess full-fledged cristae. However, there are no reports that the mitochondria of the aerobic Heterolobosea can form stacks like the hydrogenosomes of P. lanterna.

The molecular data, which are summarized in Table 1, also support the similarity between the hydrogenosomes of $P$. lanterna and the mitochondria of the aerobic Heterolobosea since the mitochondrial proteins Hsp60 and Propionyl-CoA Carboxylase B of Psalteriomonas lanterna are closely related to their homologues of Naegleria gruberi. The close phylogenetic relationship between Psalteriomonas lanterna and Naegleria gruberi had also been shown by the analysis of the 18S rRNA [21].

The presence of a PFO, a [FeFe]hydrogenase, a putative alternative ADP/ATP translocator and the $51 \mathrm{kD}$ subunit of mitochondrial complex I are characteristic hallmarks of a hydrogenosomal metabolism resembling that of Trichomonas vaginalis and Trimastix pyriformis $[17,28]$. How- 


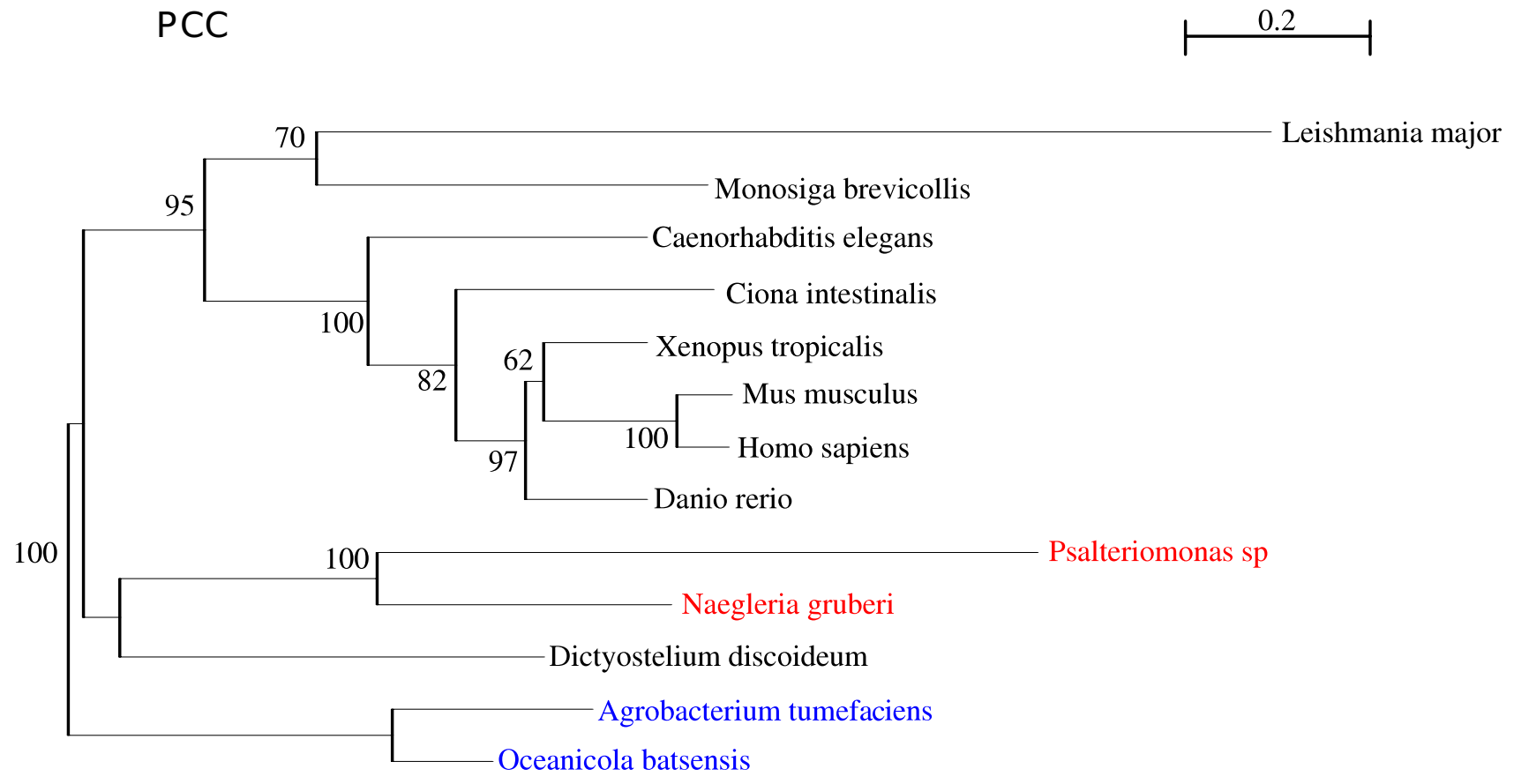

\section{Figure 9}

ML phylogenetic tree of Propionyl Co-A carboxylase (PCCB). Branch values are bootstrap support. This tree is rooted by 2 archaeal species, and was computed using a WAG+4 discrete-rate $\mathrm{G}+\mathrm{I}$ model.

ever, this is the first report of a PFO in a hydrogenosome that is clearly derived from an aerobic mitochondrion. This allows the development of a rudimentary metabolic scheme (Fig. 12). The decarboxylation of pyruvate by PFO yields electrons, which, analogous to the situation in Trichomonas [17], requires a ferredoxin like protein similar to the one described earlier [27]. However, Blast analysis of the published ferredoxin sequence fails to reveal homologies with well-characterized ferredoxins. Moreover, the AT content of the gene is dramatically lower than that of other genes analysed in this study. Finally, an analysis of the codon usage with the aid of a principal component analysis clearly excludes the published ferredoxin sequence from the cluster of Psalteriomonas genes (not shown). Therefore, it is very unlikely that the published sequence is a Psalteriomonas ferredoxin, and, consequently, a genuine ferredoxin of $P$. lanterna still awaits detection.

Consequently, the transfer of the electrons from the PFO to the hydrogenase in our scheme (Fig. 12) remains unclear. It is possible that the $51 \mathrm{KDa}$ protein might be involved since it can function as a diaphorase $[17,59,62]$.

In conclusion, both the morphology of the hydrogenosomes and the molecular data strongly support the inter- pretation that the hydrogenosomes of Psalteriomonas lanterna and the mitochondria of the aerobic Heterolobosea share a common ancestor. The hydrogenosomes of Trichomonas are metabolically similar, but morphologically distinct, and they represent a peculiar type of hydrogenosome that lacks related mitochondrial relatives. Also the hydrogenosomes of ciliates and chytridiomycete fungi are different. And since the hydrogenosomes of the ciliate Nyctotherus ovalis share a common ancestry with ciliate mitochondria, while the hydrogenosomes of the anaerobic chytrids Neocallimastix and Piromyces share an ancestry with fungal mitochondria, our study provides a new example of the evolution of a hydrogenosome from an aerobic relative [14], and the first example of a Trichomonas-like hydrogenosome from an aerobic mitochondrion.

\section{Methods}

\section{Cultivation of Psalteriomonas lanterna}

Psalteriomonas lanterna was isolated from anoxic sediment from a sedimentation pond of a waste water treatment plant near Nijmegen about 20 years ago and cultured since then as a polyxenic culture. Bottles of $100 \mathrm{ml}, 250$ $\mathrm{ml}, 500 \mathrm{ml}$ and $1000 \mathrm{ml}$ were filled to $40 \%$ with $5 \mathrm{mM}$ phosphate buffer (pH 6.8), $0.1 \mathrm{mM}$ cysteine-HCl, $1 \mathrm{ml} / \mathrm{l}$ Pfennigs metal solution, $0.025 \%$ proteose pepton and 


\section{Mitochondrial Complex I 51kDa subunit}

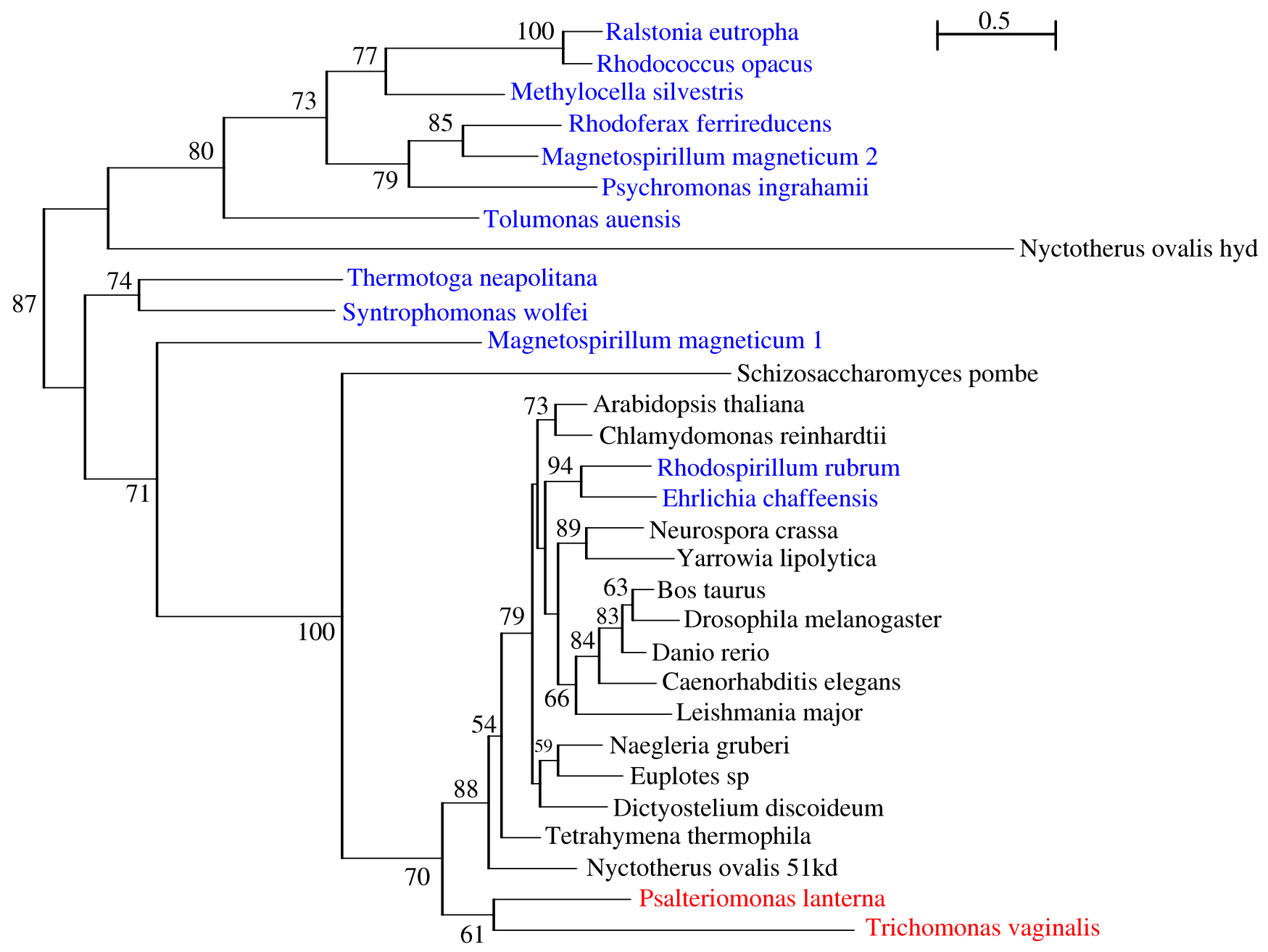

Figure 10

NADH:ubiquinone oxidoreductase 5 I $\mathrm{kDa}$ subunit ML phylogeny with bootstrap values indicated in the branches, and computed using a WAG+4 discrete-rate $G$.

Resazurine ( $50 \mathrm{pM} \mathrm{w/v).} \mathrm{The} \mathrm{bottles} \mathrm{were} \mathrm{stoppered} \mathrm{with}$ butyl-rubber stoppers, evacuated, flushed with $\mathrm{N}_{2}$ and filled with this gas until a final pressure of 1.5 Bar. These bottles were sterilized and inoculated with Psalteriomonas lanterna cells. Oxygen was added until a final concentration of $1 \%$. Twice a week bottles were checked; if they were completely anaerobic, oxygen was added up to $1 \%$. The bottles were stored at $22^{\circ} \mathrm{C}$ and exposed to light every day for several hours.

\section{Generation of the EST library}

Cells were harvested by centrifugation at room temperature in $50 \mathrm{ml}$ glass tubes in a Hettich centrifuge for $5 \mathrm{~min}$ utes at 2000 r.p.m.. The supernatant was removed and the cell pellet was immediately dissolved in $8 \mathrm{M}$ guanidin- iumchloride (final concentration 6M). RNA was isolated and cleaned with the RNeasy Kit (Qiagen). The cDNA was created with the "SMART"- technology (BD Biosciences). The produced cDNA was amplified. Then the cDNA was restricted with Sfi I and size fractionated (fraction 1-2.5 kb and $>2.5 \mathrm{~kb}$ ). The DNA fragments were cloned sitedirected. For the transformation we used competent $E$. coli DH10B cells. The library was generated by Genterprise, Mainz, Germany. About 480 randomly chosen clones were sequenced and analyzed using the BLAST X tool [36]. The A+T content was calculated, and clones with an A+T content of approximately $67-72 \%$ were regarded as derived from Psalteriomonas lanterna. The EST sequences varied largely in length and, in general, were incomplete. 


\section{Glutamate Dehydrogenase}
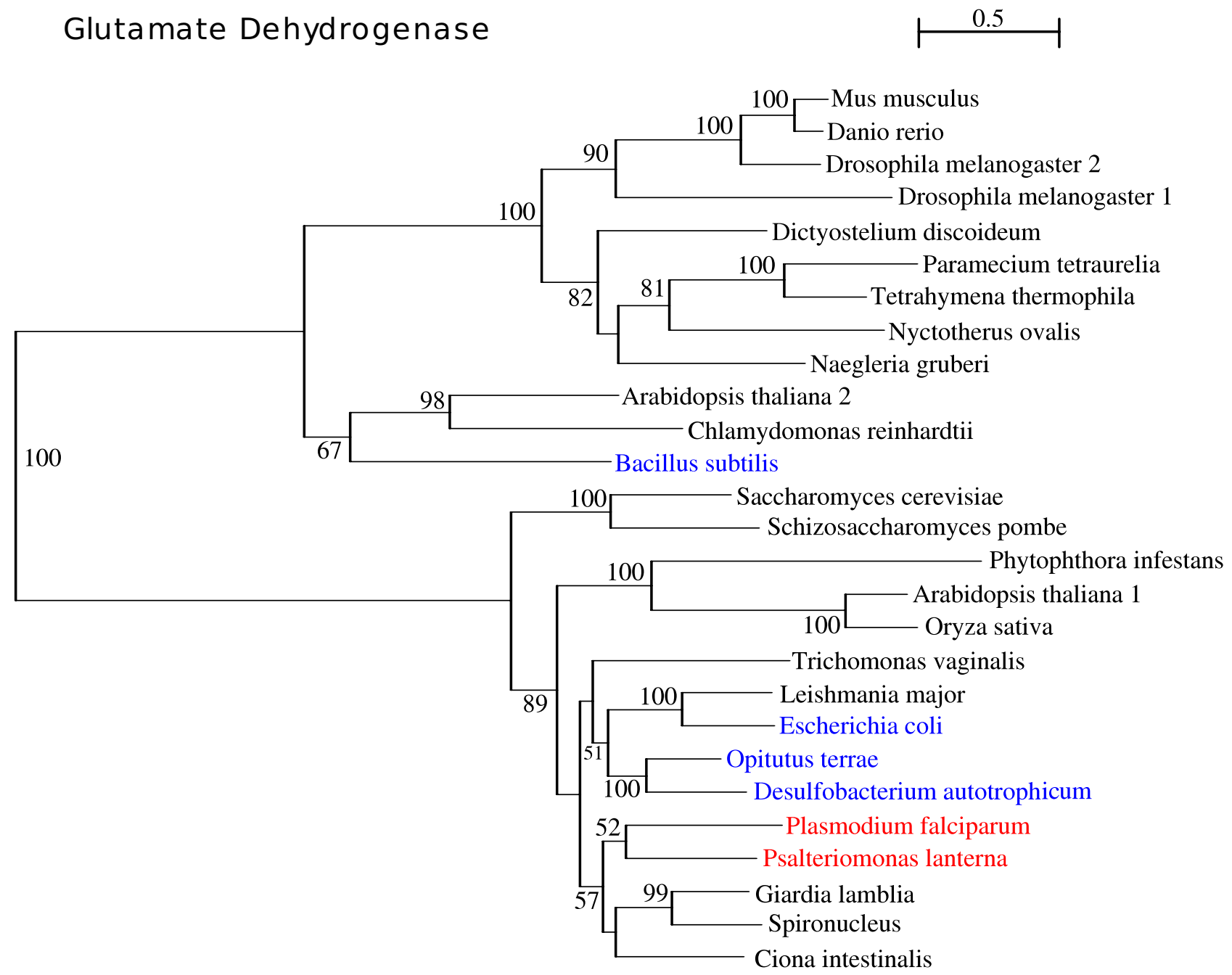

Figure I I

Phylogenetic tree of the Glutamate dehydrogenase computed by ML with a RtREV+4 discrete-rate G+I+F. Branches show the bootstrap support values.

\section{Generation of full-length cDNA}

The sequence of the [FeFe] hydrogenase was nearly completed to the $\mathrm{N}$ - and $\mathrm{C}$-terminal ends starting from the $\mathrm{H}$ cluster (that was sequenced earlier [63]). Total RNA was isolated from Psalteriomonas cells using the RNeasy kit (Qiagen) according to the manufacturer's manual and subsequently, cDNA was generated using SuperScript (Invitrogen) and an anchored oligo-d(T) primer. Alternatively, SMART RNA amplification (Clontech) was used to generate (near) full-length cDNA sequences from all genes discussed here except $51 \mathrm{kDa}$.

\section{Electron microscopy}

The electron microscopic preparations followed a modified Karnovsky procedure (4\% paraformaldehyde and 5\% glutardialdehyde in phosphate buffer $\mathrm{pH}$ 7.2). For post- fixation, the $\mathrm{OsO}_{4} / \mathrm{K}_{3} \mathrm{Fe}(\mathrm{CN})_{6}$ method of Hepler [64] was applied. En block staining was performed with $2 \%$ uranyl acetate. After embedding in Epon 812 [65], sections were made on a Reichert Om U2 ultramicrotome, stained with lead citrate and uranyl acetate, and examined in a Zeiss 109 T electron microscope.

\section{Sequence data retrieval and alignment}

The longest ORF from the conceptual translation (universal genetic code) of the ESTs of Psalteriomonas was obtained for each gene using Expasy's Translate tool http:/ /www.expasy.org/tools/dna.html. The genes received the following GenBank accession numbers: $51 \mathrm{kd}$ : GQ924927, ADP/ATP carrier: GQ924928, PCCB: GQ924929, hydrogenase: GQ924930, PFO: GQ924931, elongation factor alpha: GQ924932, Hsp60: GQ924933, 
Table I: Presence of hydrogenosomal genes of $P$. lanterna in various genomes

\begin{tabular}{|c|c|c|c|c|c|c|c|c|c|c|c|c|c|c|c|}
\hline & \multicolumn{8}{|c|}{ Mitochondrion } & \multicolumn{3}{|c|}{ Mitosome } & \multicolumn{4}{|c|}{ Hydrogenosome } \\
\hline & Hsa & Sce & Tth & Pte & Pfa & Ngr & Lma & Cpa & Ecu & Gla & Ehi & Tra & Nov & Pla & Nfr \\
\hline EFI-alpha & $Y$ & $Y$ & $Y$ & $Y$ & $Y$ & $Y$ & $Y$ & $Y$ & $Y$ & $Y$ & $Y$ & $Y$ & $Y$ & $Y$ & $Y$ \\
\hline Hsp60 & $Y$ & $Y$ & $Y$ & $Y$ & $Y$ & $Y$ & $Y$ & $Y$ & $\mathrm{~N}$ & $Y$ & $Y$ & $Y$ & $Y$ & $Y$ & $Y$ \\
\hline AAC & $Y$ & $Y$ & $Y$ & $Y$ & $Y$ & $Y$ & $Y$ & $Y$ & $Y^{*}$ & $\mathrm{~N}$ & $Y^{*}$ & $Y^{*}$ & $Y$ & $Y^{*}$ & $Y$ \\
\hline [FeFe]hydrogen. & $\mathrm{N}$ & $\mathrm{N}$ & $N$ & $N$ & $N$ & $Y$ & $\mathrm{~N}$ & $\mathrm{~N}$ & $N$ & $Y$ & $Y$ & $Y$ & $\mathrm{Y}$ & $Y$ & $Y$ \\
\hline PFO & $\mathrm{N}$ & $N$ & $N$ & $\mathrm{~N}$ & $\mathrm{~N}$ & $\mathrm{~N}$ & $N$ & $Y^{*}$ & $\mathrm{~N}$ & $Y$ & $Y$ & $Y$ & $\mathrm{~N}$ & $Y$ & $\mathrm{~N}$ \\
\hline $\mathrm{PCCB}$ & $Y$ & $N$ & $Y$ & $Y$ & $\mathrm{~N}$ & $Y$ & $Y$ & $N$ & $N$ & $\mathrm{~N}$ & $\mathrm{~N}$ & $\mathrm{~N}$ & - & $Y$ & - \\
\hline $51 \mathrm{kDa}$ & $Y$ & $N$ & $Y$ & $Y$ & $N$ & $Y$ & $Y$ & $\mathrm{~N}$ & $\mathrm{~N}$ & $\mathrm{~N}$ & $\mathrm{~N}$ & $Y$ & $Y$ & $Y$ & - \\
\hline GDH & $Y$ & $Y$ & $Y$ & $Y$ & $Y$ & $Y$ & $Y$ & $N$ & $N$ & $Y$ & $Y$ & $Y$ & $Y$ & $Y$ & - \\
\hline
\end{tabular}

Hsa: Homo sapiens, Sce: Saccharomyces cerevisiae, Tth: Tetrahymena thermophila, Pte: Paramecium tetraurelia, Pfa: Plasmodium falciparum, Ngr: Naegleria gruberi, Lma: Leishmania major, Cpa: Cryptosporidium parvum, Ecu: Encephalitozoon cuniculi, Gla: Giardia lamblia, Ehi: Entamoeba histolytica, Tva: Trichomonas vaginalis, Nov: Nyctotherus ovalis\$; Pla: Psalteriomonas lanterna $\$$, Nfr: Neocallimastix frontalis\$.

Y: present, N: absent, $Y^{*}$ : alternative protein, -: not known;\$: no complete genome available

and Glutamate dehydrogenase GQ924934. Its homologous protein sequences were retrieved from GenBank nr database, using PsiBLAST [36] with 0.005 e-value cut-off and after three iterations. Sequences from Naegleria gruberi were collected from its genome project webpage http:// genome.jgi-psf.org/Naegr1/Naegr1.home.html.
Sequences were aligned with ClustalW (version 1.83) [66], and manually inspected and refined.

\section{Construction of phylogenetic trees}

Given the large number of sequences retrieved by homology search, a restricted number of taxa, representing the

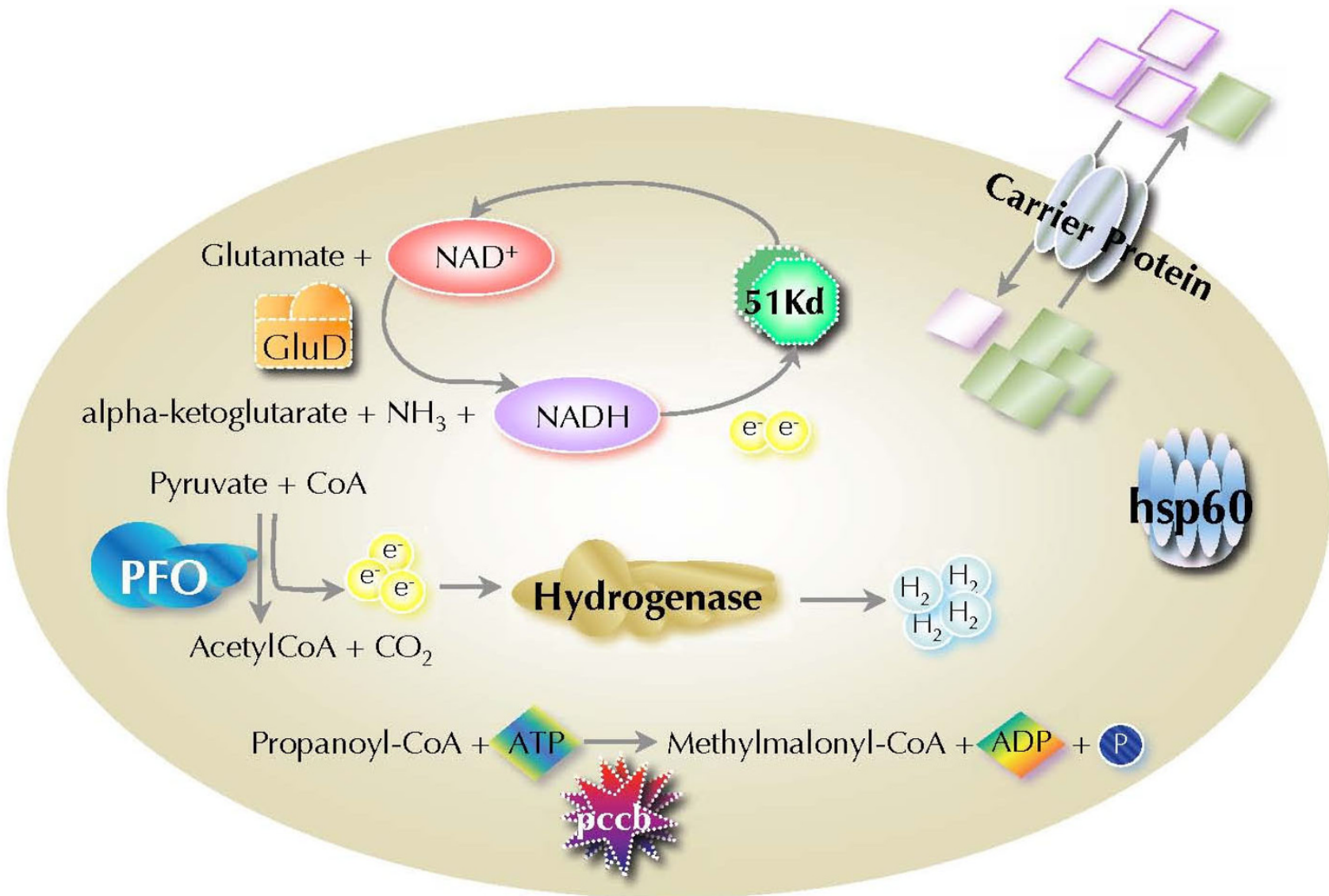

Figure 12

Rudimentary metabolic scheme of the hydrogenosomes of $P$. Ianterna. 
major Eukaryotic branches, were selected to integrate the phylogenetic study. In order to facilitate this selection, a preliminary analysis of the complete dataset was carried out by inspecting the global topology of 1000 times bootstrapped Neighbour-Joining trees, computed with ClustalW [66]. When possible, a small outgroup of prokaryotic sequences was included to root the trees. After the careful selection of the final dataset, we pursued to select the bestfit model of amino acid replacement, according to the Akaike Information Criterion (AIC) as implemented in the ProtTest (version 2.2) software [67]. Maximum Likelihood (ML) phylogenies were computed with PhyML (version 2.4.4) [68], using the model previously chosen. (For the detailed description of the model and parameters used for each phylogenetic inference, including the matrix of aa substitution; number of Gamma discrete rate-categories $(+\mathrm{G})$; proportion of invariable sites $(+\mathrm{I})$ and observed amino acid frequencies $(+\mathrm{F})$, see figure captions). A bootstrap analysis was conducted with 100 samples for each protein.

\section{Codon Usage and Principle Component Analysis}

In order to rule out the presence of contaminants in the EST set, we performed a codon usage analysis using the Cusp program from the EMBOSS package (version 6.0.1) [37]. We also included in our analysis the ferredoxin sequence previously published by Brul et al. [27] to analyse whether it is of Psalteriomonas origin or not. A principle component analysis was conducted using the prcomp function of the $\mathrm{R}$ package ( $\mathrm{R}$ Development Core Team, 2008).

\section{Authors' contributions}

RMdG coordinated the molecular analysis, participated in sequencing of the ESTs and drafted the manuscript. ID analyzed the genetic code, performed the bioinformatic analysis and participated in drafting the manuscript. JR and JHPH performed the electron microscopy. TvA participated in sequencing and analyzing the ESTs and cultured the Psalteriomonas cells. JK and KS participated in cloning, sequencing and analyzing the hydrogenase gene. MAH supervised the phylogenetic analysis and participated in drafting the manuscript. JHPH initiated and coordinated the study and participated in drafting the manuscript. All authors read and approved the final manuscript.

\section{Acknowledgements}

The Naegleria sequence data used were produced by the US Department of Energy Joint Genome Institute http://www.jgi.doe.gov/. This work was supported by the BioRange programme of The Netherlands Bioinformatics Centre (NBIC). We thank Holger Schlierenkamp, University of Bochum, for excellent technical support in electron microscopy, and Prof. emer. Alan Schwartz for revising the English phrasing. Claudius Stumm provided the photograph shown in Fig. Ia. Isabel Duarte was funded by the scholar- ship SFRH/BD/32959/2006 from the Portuguese Foundation for Science and Technology - FCT.

\section{References}

I. Stechmann A, Hamblin K, Perez-Brocal V, Gaston D, Richmond GS, Giezen $M$ van der, Clark CG, Roger AJ: Organelles in Blastocystis that blur the distinction between mitochondria and hydrogenosomes. Curr Biol 2008, I 8(8):580-585.

2. Keithly J: The mitochondrion related organelle of Cryptosporidium parvum. In Hydrogenosomes and mitosomes: mitochondria of anaerobic eukaryotes Volume 9. Edited by: Tachezy J. Berlin Heidelberg: Springer-Verlag; 2008:231-253.

3. Muller M: The hydrogenosome. J Gen Microbiol 1993, I39( I 2):2879-2889.

4. Tovar J, Fischer A, Clark CG: The mitosome, a novel organelle related to mitochondria in the amitochondrial parasite Entamoeba histolytica. Mol Microbiol 1999, 32(5): I013-1021.

5. Tovar J, Leon-Avila G, Sanchez LB, Sutak R, Tachezy J, Giezen M van der, Hernandez M, Muller M, Lucocq JM: Mitochondrial remnant organelles of Giardia function in iron-sulphur protein maturation. Nature 2003, 426(6963): I72-I76.

6. Williams BA, Hirt RP, Lucocq JM, Embley TM: A mitochondrial remnant in the microsporidian Trachipleistophora hominis. Nature 2002, 4 I 8(6900):865-869.

7. Howe C): Cellular evolution: what's in a mitochondrion? Curr Biol 2008, I 8(1 0):R429-43I.

8. Gill EE, Diaz-Trivino S, Barbera MJ, Silberman JD, Stechmann A, Gaston D, Tamas I, Roger AJ: Novel mitochondrion-related organelles in the anaerobic amoeba Mastigamoeba balamuthi. Mol Microbiol 2007, 66(6): I306-I320.

9. Goldberg AV, Molik S, Tsaousis AD, Neumann K, Kuhnke G, Delbac F, Vivares CP, Hirt RP, Lill R, Embley TM: Localization and functionality of microsporidian iron-sulphur cluster assembly proteins. Nature 2008, 452(7187):624-628.

10. Aguilera P, Barry T, Tovar J: Entamoeba histolytica mitosomes: organelles in search of a function. Exp Parasitol 2008, I I 8(I): $10-16$.

II. Hackstein JH, de Graaf RM, van Hellemond J], Tielens A GM: Hydrogenosomes of Anaerobic Ciliates. In Hydrogenosomes and Mitosomes: Mitochondria of Anaerobic Eukaryotes Volume 9. Edited by: Tachezy J. Berlin Heidelberg: Springer-Verlag; 2008:97-II2.

12. Hackstein JHP, Baker S E, van Hellemond J J, Tielens A GM: Hydrogenosomes of Anaerobic Chytrids: An Alternative Way to Adapt to Anaerobic Environments. In Hydrogenosomes and Mitosomes: Mitochondria of Anaerobic Eukaryotes Volume 9. Edited by: Tachezy J. Berlin Heidelberg: Springer-Verlag; 2008:147-162.

13. Hackstein JH, Akhmanova A, Voncken FG, van Hoek AH, van Alen TA, Boxma B, Moon-van der Staay SY, Staay GW van der, Leunissen J, Huynen MA, et al.: Hydrogenosomes: convergent adaptations of mitochondria to anaerobic environments. Zoology 200I, I 04(3-4):290-302.

14. Hackstein JH, Tjaden J, Huynen MA: Mitochondria, hydrogenosomes and mitosomes: products of evolutionary tinkering! Curr Genet 2006, 50(4):225-245.

15. Boxma B, Voncken F, Jannink S, van Alen T, Akhmanova A, van Weelden S, van Hellemond J, Ricard G, Huynen M, Tielens A, et al.: The anaerobic chytridiomycete fungus Piromyces sp. E2 produces ethanol via pyruvate:formate lyase and an alcohol dehydrogenase E. Mol Microbiol 2004, 5 I (5): I389-I399.

16. Boxma B, de Graaf RM, Staay GW van der, van Alen TA, Ricard G, Gabaldon T, van Hoek AHAM, Moon-van der Staay SY, Koopman W], van Hellemond Jj, et al.: An anaerobic mitochondrion that produces hydrogen. Nature 2005, 434(7029):74-79.

17. Carlton JM, Hirt RP, Silva JC, Delcher AL, Schatz M, Zhao Q, Wortman JR, Bidwell SL, Alsmark UC, Besteiro S, et al.: Draft genome sequence of the sexually transmitted pathogen Trichomonas vaginalis. Science 2007, 3 I 5(5809):207-2I2.

18. Embley TM, Martin W: Eukaryotic evolution, changes and challenges. Nature 2006, 440(7084):623-630.

19. Boxma B, Ricard G, van Hoek AH, Severing E, Moon-van der Staay SY, Staay GW van der, van Alen TA, de Graaf RM, Cremers G, Kwantes $M$, et al:: The [FeFe] hydrogenase of Nyctotherus ovalis has a chimeric origin. BMC Evol Biol 2007, 7:230. 
20. Broers CAM, Stumm CK, Vogels GD, Brugerolle G: Psalteriomonas Lanterna gen. nov., sp. nov., A free-living amoeboflagellate isolated from fresh-water anaerobic sediments. Eur J Protistol 1990, 25(4):369-380.

21. Weekers PH, Kleyn J, Vogels GD: Phylogenetic position of Psalteriomonas lanterna deduced from the SSU rDNA sequence. J Eukaryot Microbiol I997, 44(5):467-470.

22. Moon-van der Staay SY, Tzeneva VA, Staay GW van der, de Vos WM, Smidt $\mathrm{H}$, Hackstein $\mathrm{JH}$ : Eukaryotic diversity in historical soil samples. FEMS Microbiol Ecol 2006, 57(3):420-428.

23. O'Kelly CJ, Silberman JD, Amaral Zettler LA, Nerad TA, Sogin ML: Monopylocystis visvesvarai $n$. gen., $n$. sp. and Sawyeria marylandensis n. gen., n. sp.: two new amitochondrial heterolobosean amoebae from anoxic environments. Protist 2003 I 54(2):28I-290.

24. Smirnov AV, Fenchel T: Vahlkampfia anaerobica $\mathbf{n}$ sp and Vannella peregrinia $n$ sp (Rhizopoda) - Anaerobic amoebae from a marine sediment. Arch fur protistenkunde 1996, I47(2): I89-198.

25. Broers CAM: Anaerobic psalteriomonad amoeboflagellates. In PhD Thesis Nijmegen: Catholic University Nijmegen; 1992.

26. Zwart KB, Goosen NK, van Schijndel MW, Broers CAM, Stumm CK, Vogels GD: Cytochemical localization of hydrogenase activity in the anaerobic protozoa Trichomonas vaginalis, Plagiopyla nasuta and Trimyema compressum. J Gen Microbiol 1988, I34:2165-2170.

27. Brul S, Veltman RH, Lombardo MC, Vogels GD: Molecular cloning of hydrogenosomal ferredoxin cDNA from the anaerobic amoeboflagellate Psalteriomonas lanterna. Biochim Biophys Acta 1994, I I 83(3):544-546.

28. Hampl V, Silberman JD, Stechmann A, Diaz-Trivino S, Johnson PJ, Roger AJ: Genetic evidence for a mitochondriate ancestry in the 'amitochondriate' flagellate Trimastix pyriformis. PLoS ONE 2008, 3(I): el 383.

29. Doddema HJ, Vogels GD: Improved identification of methanogenic bacteria by fluorescence microscopy. Appl Environ Microbiol 1978, 36(5):752-754.

30. Brugerolle G, Simpson AG: The flagellar apparatus of heteroloboseans. J Eukaryot Microbiol 2004, 5 I (1):96- 107.

31. Page FC, Blanton RL: The heterolobosea (Sarcodina, Rhizopoda), a new class uniting the Schizopyrenida and the Acrasidae. Protistologica 1985, 2 1(1): 121-132.

32. Nielsen MH, Diemer NH: The size, density, and relative area of chromatic granules ("hydrogenosomes") in Trichomonas vaginalis Donne from cultures in logarithmic and stationary growth. Cell Tissue Res 1976, 167(4):461-465.

33. Jurland $A$, Lipps $\mathrm{HJ}$ : Two types of mitochondria in Euplotes minuta. Arch Protistenk 1973, I I 5:SI 33-136.

34. Görtz HD: Untersuchungen zur Feinstruktur von Euplotes minuta Yocum (Ciliata, Hypotrichida) unter besonderer Berücksichtigung von Cortexstrukturen. In PhD thesis Münster: University of Münster; 1975.

35. Fuller M: Spermatogenesis. In The development of Drosophila New York: Cold Spring Harbor press; 1993:7I- 147.

36. Altschul SF, Madden TL, Schaffer AA, Zhang J, Zhang Z, Miller W, Lipman DJ: Gapped BLAST and PSI-BLAST: a new generation of protein database search programs. Nucleic Acids Res 1997, 25(I7):3389-3402.

37. Rice P, Longden I, Bleasby A: EMBOSS: the European Molecular Biology Open Software Suite. Trends Genet 2000, 16(6):276-277.

38. Nilsson J, Nissen P: Elongation factors on the ribosome. Current Opinion in Structural Biology 2005, I 5(3):349-354.

39. Emelyanov VV: Phylogenetic relationships of organellar Hsp90 homologs reveal fundamental differences to organellar Hsp70 and Hsp60 evolution. Gene 2002, 299(I-2): I 25- 133.

40. Saibil HR: Chaperone machines in action. Current Opinion in Structural Biology 2008, 18(1):35-42.

41. Karlin S, Brocchieri L: Heat shock protein 60 sequence comparisons: duplications, lateral transfer, and mitochondrial evolution. Proc Natl Acad Sci USA 2000, 97(2 I): I I348-I I 353.

42. Hampl V, Hug L, Leigh JW, Dacks JB, Lang BF, Simpson AG, Roger AJ: Phylogenomic analyses support the monophyly of Excavata and resolve relationships among eukaryotic "supergroups". Proc Natl Acad Sci USA 2009, 106(10):3859-3864.

43. Kunji ER: The role and structure of mitochondrial carriers. FEBS Lett 2004, 564(3):239-244.
44. Haferkamp I, Hackstein J, Voncken F, Schmit G, Tjaden J: Functional integration of mitochondrial and hydrogenosomal ADPIATP carriers in the Escherichia coli membrane reveals different biochemical characteristics for plants, mammals and anaerobic chytrids. Eur J Biochem 2002, 269(13):3172-3I8I.

45. Kamp C, Silakov A, Winkler M, Reijerse EJ, Lubitz W, Happe T: Isolation and first EPR characterization of the [FeFe]-hydrogenases from green algae. Biochim Biophys Acta 2008, 1777(5):410-416.

46. Horner DS, Heil B, Happe T, Embley TM: Iron hydrogenases-ancient enzymes in modern eukaryotes. Trends in biochemical sciences 2002, 27(3): $148-153$

47. Meyer J: [FeFe] hydrogenases and their evolution: a genomic perspective. Cell Mol Life Sci 2007, 64(9): I063-1084.

48. Menon S, Ragsdale SW: Mechanism of the Clostridium thermoaceticum pyruvate:ferredoxin oxidoreductase: evidence for the common catalytic intermediacy of the hydroxyethylthiamine pyropyrosphate radical. Biochemistry 1997, 36(28):8484-8494.

49. Moulis JM, Davasse V, Meyer J, Gaillard J: Molecular mechanism of pyruvate-ferredoxin oxidoreductases based on data obtained with the Clostridium pasteurianum enzyme. FEBS Lett 1996, 380(3):287-290.

50. Müller M: Enzymes and compartmentation of core energy metabolism of anaerobic protists - a special case in eukaryotic evolution? In Evolutionary relationships among protozoa Edited by: Coombs GH, Vickerman K, Sleigh MA, Warren A. Dordrecht, the Netherlands: Kluwer; 1998: 109-132.

5I. Lantsman Y, Tan KS, Morada M, Yarlett N: Biochemical characterization of a mitochondrial-like organelle from Blastocystis sp. subtype 7. Microbiology 2008, I 54(Pt 9):2757-2766.

52. Jiang H, Rao KS, Yee VC, Kraus JP: Characterization of four variant forms of human propionyl-CoA carboxylase expressed in Escherichia coli. J Biol Chem 2005, 280(30):277 |9-27727.

53. Schrick JJ, Lingrel JB: cDNA cloning, mapping and expression of the mouse propionyl CoA carboxylase beta (pccb), the gene for human type II propionic acidaemia. Gene 200I, 264(I): $147-152$.

54. McGrath CL, Zufall RA, Katz LA: Variation in macronuclear genome content of three ciliates with extensive chromosomal fragmentation: a preliminary analysis. J Eukaryot Microbiol 2007, 54(3):242-246.

55. Ricard G: Evolution and genome structure of anaerobic ciliates. In Thesis Nijmegen: Radboud University; 2008.

56. Gabaldon T, Rainey D, Huynen MA: Tracing the evolution of a large protein complex in the eukaryotes, NADH:ubiquinone oxidoreductase (Complex I). J Mol Biol 2005, 348(4):857-870.

57. Vogel RO, Smeitink JA, Nijtmans LG: Human mitochondrial complex I assembly: a dynamic and versatile process. Biochim Biophys Acta 2007, 1767(10): 1215-1227.

58. Schuelke M, Smeitink J, Mariman E, Loeffen J, Plecko B, Trijbels F, Stockler-Ipsiroglu S, Heuvel L van den: Mutant NDUFV I subunit of mitochondrial complex I causes leukodystrophy and myoclonic epilepsy. Nat Genet 1999, 2 I(3):260-26I.

59. Hrdy I, Hirt RP, Dolezal P, Bardonova L, Foster PG, Tachezy J, Embley TM: Trichomonas hydrogenosomes contain the NADH dehydrogenase module of mitochondrial complex I. Nature 2004, 432(70|7):618-622.

60. Frigerio F, Casimir M, Carobbio S, Maechler P: Tissue specificity of mitochondrial glutamate pathways and the control of metabolic homeostasis. Biochim Biophys Acta 2008, 1777(7-8):965-972

61. Andersson JO, Roger AJ: Evolution of glutamate dehydrogenase genes: evidence for lateral gene transfer within and between prokaryotes and eukaryotes. BMC Evol Biol 2003, 3:14.

62. Dyall SD, Yan W, Delgadillo-Correa MG, Lunceford A, Loo JA, Clarke CF, Johnson PJ: Non-mitochondrial complex I proteins in a hydrogenosomal oxidoreductase complex. Nature 2004, 43 I (70 I 2): I I03-II 07

63. Voncken FG, Boxma B, van Hoek AH, Akhmanova AS, Vogels GD, Huynen MA, Veenhuis M, Hackstein JH: A hydrogenosomal [Fe]hydrogenase from the anaerobic chytrid Neocallimastix sp. L2. Gene 2002, 284(I-2): I03-II2.

64. Hepler PK: The structure of the endoplasmic reticulum revealed by osmium tetroxide-potassium ferricyanide staining. Eur J Cell Biol I98I, 26(I): I02-IIII. 
65. Luft JH: Improvements in epoxy resin embedding methods. J Biophys Biochem Cytol I96I, 9:409-4I4.

66. Thompson JD, Higgins DG, Gibson TJ: CLUSTAL W: improving the sensitivity of progressive multiple sequence alignment through sequence weighting, position-specific gap penalties and weight matrix choice. Nucleic Acids Res 1994, 22(22):4673-4680.

67. Abascal F, Zardoya R, Posada D: ProtTest: selection of best-fit models of protein evolution. Bioinformatics 2005, 2I(9):2104-2105.

68. Guindon $S$, Gascuel $O$ : A simple, fast, and accurate algorithm to estimate large phylogenies by maximum likelihood. Systematic Biology 2003, 52(5):696-704.

Publish with Bio Med Central and every scientist can read your work free of charge

"BioMed Central will be the most significant development for disseminating the results of biomedical research in our lifetime. "

Sir Paul Nurse, Cancer Research UK

Your research papers will be:

- available free of charge to the entire biomedical community

- peer reviewed and published immediately upon acceptance

- cited in PubMed and archived on PubMed Central

- yours - you keep the copyright

Submit your manuscript here:

http://www.biomedcentral.com/info/publishing_adv.asp
BioMedcentral 